\title{
Introduction
}

\author{
Virginia Santamarina Campos, María de Miguel Molina \\ and Stephan Kröner
}

\begin{abstract}
The aim of this book is to disseminate part of the results of the H2020 European Project AiRT (Technology Transfer of RPAs for the Creative Industry). In particular, we want to present some results to mitigate safety and security concerns when piloting civil drones in the service sector. European policies concerning drones in general are focused on outdoor drone use, but drones can also be employed indoors. Moreover, European countries have fragmented regulations about the use of drones; therefore, European institutions are endeavouring to combine all these regulations. In this sense not only law but also ethics play a key role in providing the industry with guidelines to gain citizens' trust. Therefore, our work is based on four pillars:

1. An analysis of the drone sector in Europe;

2. An in-depth study of the European policies;

3. A comparative analysis of the regulations of some European countries;

4. Primary data from members of the creative industry.
\end{abstract}

With these results we would like to give advice to the European industry as well as providing new insights for policy makers and the scientific community. The project has received funding from the European Union's Horizon 2020 research and innovation programme under grant agreement no. 732433 (reference: H2020-ICT2016-2017, www.airt.eu). This book reflects the views of the authors and not necessary the position of the Commission.

\section{Scope of the Book}

The AiRT project runs from January 2017 to June 2018. The consortium brings together a group of partners from three European countries with a complementary and outstanding range of experiences, skills, competences, and resources.

V. Santamarina Campos $(\bowtie) \cdot$ M. de Miguel Molina $\cdot$ S. Kröner

Universitat Politècnica de València, Valencia, Spain

e-mail: virsanca@upv.es 
The Universitat Politècnica de València (UPV, Spain) combines experts in creative industries (CIs) on one hand and specialists in robotics and innovative information and communication technology (ICT) solutions on the other hand. From the perspective of specialists in creative activities and aerial filming, Clearhead Media Ltd (UK) has experience in the use of RPASs as a professional filming tool for outdoor purposes. AeroTools UAV-Unmanned Aerial Vehicles (Spain) specializes in developing RPAS systems. It relies on substantial experience in the development of RPAS operation systems, which include advanced functionalities such as automatic obstacle detection, encrypted communication systems, and autonomous RPAS navigation. Pozyx Labs BVBA (Belgium) has developed a novel IPS (indoor positioning system) with which highly precise indoor coordinates can be obtained.

Why is a book on good practices needed?

As will be illustrated very clearly in the second chapter, the drone market presents a real opportunity to foster job creation and a source of innovation and economic growth. For Europe, for instance, about 150,000 jobs are forecast by the AeroSpace and Defence Industries Association of Europe by 2050, excluding employment generated through operator services (European Commission 2014). However, the EU Subcommittee on Civil Use of Drones believes that this approach to estimating job creation through drone operations results in significant underestimations, since it excludes completely new areas of activity that are not necessarily classified as aviation (e.g. surveys, creative industry activities, etc.) (House of Lords 2014). Moreover, the drone industry will not only create new qualified jobs but will foster the emergence of a totally new service industry offering drone operations and aerial work to commercial and state customers. Nevertheless, the legal situation differs in each European country, and technology advances require fast adaption of laws, since special flight environments, like confined spaces, are mostly not considered. These legal uncertainties hinder the exploitation, especially in Europe, of this big and very dynamic market.

Consequently, one focus of this book is the elaboration of a proposal for European legislation for indoor RPAS safety, including both ethical/security and safety risk issues. It will provide recommendations for policies for the European regions and the EU Government, including recommendations to alter the law where necessary and to overcome obstacles (if found) that hinder the use of drones indoors. Although this might seem to be a very challenging task at first glance, when we analysed indoor issues, we reached the conclusion that many of them can be treated in the same way as when operating outdoors. Apart from that, we noticed that, in some European countries, small indoor drones are not considered by any regulation with the exception of professional work.

To which types of drones are the recommendations described in the following chapters of this book addressed?

As will be explained in more detail in the chapter "European Union Policies and Civil Drones", the first rough subdivision/classification of drones can be made according to their mission: military or civilian. The AiRT project has the main goal of providing small and medium-sized creative industries with a drone (more precisely an RPAS - remotely piloted aircraft system) specifically designed for indoor 
use, which will enable these companies to expand their creativity and offer new and improved services. Thus, in this policy book, we focus on the civilian use of drones for professional and commercial purposes.

As will be discussed in the chapter "The Drone Sector in Europe", the drone market is very large and has tens of applications. As Hassanalian and Abdelkefi (2017) explain, drones can also be classified in the first step according to their flight zone/environment: indoors or outdoors. It has to be kept in mind that the current legislation in the different European countries mainly focuses on the regulation of outdoor use. Here we analyse the current legal state and try to provide some recommendations for proper indoor professional use as well.

Complex matters usually require the cooperation of all the different parties involved, working together in an inter-/transdisciplinary team. Thus, to provide feasible proposals, the AiRT consortium brings together partners from three European countries with complementary experiences, skills, competences, and resources. Therefore, experts in finding ICT solutions for complex topics related to robotics, pioneers in the development of ultra-wideband-based indoor positioning systems for moving objects, drone manufacturers, and specialists in creative activities and aerial filming worked together on the guideline for this good-practice book.

It is important to emphasize that the scenario for which the AiRT project was developed-flying indoors - is not specifically regulated either by the European Aviation Safety Agency (EASA) or by national aviation authorities. As a general rule, these bodies regulate the operation of aircraft only in open airspace, paying no attention to aircraft flying under a ceiling (indoors). This means that a drone operator can fly a drone inside a roofed building with no restriction, and only the permission of the owner is needed. However, this possibility normally fails, since additional issues must be taken into account, such as the civil liability of the operator or the owner in the case of an incident or accident. In other words, since the factual and legal positions are not clarified, the owner or the insurer usually refuses to grant authorization.

The definition of an "indoor space", in terms of regulated operation by civil aviation bodies, is not explicit, but it is generally accepted that indoors means any airspace under a fixed roof or ceiling that could prevent an aircraft from gaining altitude beyond this point. Whether this space has vertical walls or not is irrelevant. In terms of safety, indoor operation offers some positive aspects:

- Short range of flight.

- Always flying with visual line of sight (VLOS), although obstacles can generate shaded areas.

- Short flight time.

- Lack of meteorological variations that might disturb the flight operation.

- Enough resources at hand to provide easy operation (plugs, electrical power, short distances, easy communication, etc.). 
On the other hand, violation of privacy, particularly related to private property, such as gathering geographic information (images via satellite, aeroplanes, or drones), has always been an issue for aerial filming. Thus, to maintain high ethical standards, the consideration of ethical research conduct should be part of the project from the very beginning, as ethics are relevant at all stages. In the case of indoor use, it is essential to distinguish between private and public property. In the latter case, the permission of the people affected is a key point. Even in the case of police investigations, the concept of home intromission has been highlighted by the courts. For example, the Spanish Supreme Court (2016), in its Sentence no. 329, 2nd Room, Criminal Court, 20 April 2016, did not accept recorded images made with a drone by the police, as there was no judicial authorization or property permission to film inside that house.

\section{Brief Overview of the Different Chapters of the Book}

The chapter "The Drone Sector in Europe" illustrates the economic potential of the steadily growing drone market, in Europe as well as China and the US. The latter markets are considered to be the main ones competing with the European one, and, as can be seen in the following chapters, non-uniform European laws may lead to a competitive disadvantage of European companies, in particular SMEs. Therefore, an in-depth analysis of drone applications for professional use by different industries, such as agriculture, media, mining, energy, construction, and so on, has been performed. In addition, special attention has been paid to the creative industry sector, which is particularly affected by the legal confusion. Thus, the importance of a common European framework can be understood, and it is apparent that currently the regulatory barrier seems to be the main impediment to the definitive taking off of the drone industry (Pauner et al. 2015).

In the chapter "European Policies and Civil Drones", the authors analyse the drone policies in the European Union, providing a breakdown of the different types of actors, drones, licenses, and insurance at the European and national levels. Moreover, the ways in which all these policies affect producers and operators are considered. The problems related to licenses, the type of drone and activity, and the opportunity to have insurance can influence the development of the drone industry in the future.

In the chapter "Spain-UK-Belgium Comparative Legal Framework", the different legal frameworks from Spain, the UK, and Belgium are exposed. The CEOs (Chief Executive Officers) of the three companies participating in the project compare their regulations to illustrate the similarities and differences regarding civil drones, not only for outdoor use but also for indoor use. Here the urgency of the pending common European regulatory framework can be seen, and the authors highlight how this could reduce many of the current legal uncertainties.

The chapter "Legal and Ethical Recommendations" is dedicated to legal and above all ethical recommendations. As technology is difficult to regulate, other 
tools, such as co-regulation and self-regulation, although they can be considered as soft instruments, are useful alternatives for manufacturers and operators of civil drones (Stöcker et al 2017). As part of this project, we organized and held focus groups with drone operators in the three participating countries. Including previous research and the results of these focus group activities, the authors provide recommendations for producers, drone operators, and policy makers. The recommendations cover safety, security, and privacy aspects. Bearing in mind that at present some countries do not regulate the use of drones indoors, drone design by default and professional experience are the most important parameters to guarantee safe and secure drone flights indoors.

\section{References}

European Commission (2014) Communication from the Commission to the European Parliament and the Council. A new era for aviation. Opening the aviation market to the civil use of remotely piloted aircraft systems in a safe and sustainable manner. Available via EUR-LEX. http://eur-lex.europa.eu/legal-content/EN/TXT/?uri=CELEX\%3A52014DC0207. Accessed 8 September 2017

Hassanalian M, Abdelkefi A (2017) Classifications, applications, and design challenges of drones: a review. Prog in Aerosp Sci 91(May):99-131

House of Lords (2014) EU subcommittee B on civil use of remotely piloted aircraft systems (RPAS). Oral and written evidence. Available via Parliament. http://www.parliament.uk/civilrpas. Accessed 8 September 2017

Pauner C, Kamara I, Viguri J (2015) Drones. Current challenges and standardisation solutions in the field of privacy and data protection. ITU Kaleidosc: trust in the information society (K-2015), pp 1-7

Spanish Supreme Court (2016) Sentence no. 329, 2nd room, criminal court. Available via vLEX. https://supremo.vlex.es/vid/637465649\#section_6. Accessed 18 August 2017

Stöcker C, Bennett R, Nex F, Gerke M, Zevenbergen J (2017) Review of the current state of UAV regulations. Remote Sens 9(5):459-485

Open Access This chapter is licensed under the terms of the Creative Commons Attribution 4.0 International License (http://creativecommons.org/licenses/by/4.0/), which permits use, sharing, adaptation, distribution and reproduction in any medium or format, as long as you give appropriate credit to the original author(s) and the source, provide a link to the Creative Commons license and indicate if changes were made.

The images or other third party material in this chapter are included in the chapter's Creative Commons license, unless indicated otherwise in a credit line to the material. If material is not included in the chapter's Creative Commons license and your intended use is not permitted by statutory regulation or exceeds the permitted use, you will need to obtain permission directly from the copyright holder.

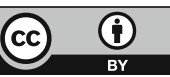

